\title{
Sustanaible Methods of Improving Kanji Learning Skills for Japanese Language Learners at Basic Level at FPT University
}

\author{
Nguyen Tan Danh* \\ FPT University, Ho Chi Minh City, Vietnam
}

\begin{abstract}
When learning Japanese, it can be said that the biggest barrier for new learners is learning Kanji. Different from Hiragana and Katakana, the number of Kanji characters is large. In writing, a lot of Kanji words have more than 20 strokes and even one Kanji has different ways of readings and meanings. When learning Kanji, learners must remember the typeface of the word, its pronunciation and its meaning. In order to be able to read and understand documents such as letters or newspapers and to communicate in Japanese in daily activities, the number of Kanji needed to learn can be up to 1000 words. This article is based on a variety of references on how to learn Kanji of foreign students, survey done by Japanese language students of different levels of current Kanji learning methods, thereby comparing, analyze current learning methods and propose methods to improve Kanji learning skills for Japanese learners at elementary level.
\end{abstract}

\section{Introduction}

In the current Covid-19 pandemic situation, the unemployment has become more and more complicated around the globe. Vietnam is one of the first successful diseasefree countries that many Japanese enterprises plan to choose as the country to shift production from China to Vietnam [1]. With this above context, studying Japanese is not only an opportunity to learn and exposure to a new culture, but also a chance to get a job with a stable salary. However, when learning Japanese, learners from the countries where their writing system is different from Chinese language, they will encounter the first difficulty which is learning Kanji characters [2]. In order to find out the most suitable methods to learn Kanji for Vietnamese people at the elementary level, the article has analyzed and compared many current methods used by Japanese learners.

${ }^{*}$ Corresponding author: hoiht@fe.edu.vn 


\section{Research content}

\subsection{Research history}

According to research by the author K. Matsumoto (2013), Japanese language learners with their first language of the alphabet system have worse results than Japanese language learners with their first language of the logographic system. He argued that Japanese language learners with an alphabetical first language decode Kanji in an inefficient way of typeface recognition. On the other hand, Japanese learners who have their first language of the logographic system can recognize Kanji thanks to their knowledge of Kanji. Many people also use phonemic decoding to identify Kanji. In addition, the reaction times in recognizing Kanji differ significantly between beginner learners and intermediate learners. The research results show that Japanese language learners with the first language alphabetic use a different reading comprehension method than the learners with their first language of the logographic system. This also happens between learners of basic level and higher levels depending on their exposure to Japanese [2].

Unlike the alphabet languages, knowledge of about 1,000 basic Kanji characters is required in order to be able to read and understand the Japanese used in newspapers and movies. Exposure to practical materials is often encouraged from an early stage of learning. This puts pressure on learning Kanji. The question is how learners can learn Kanji faster in order to take advantage of information resources in Japanese language. Learning Kanji might not be difficult, but it is extremely time consuming [3].

Kanji reading has an important influence on the learners' progress in reading comprehension. The research examines on students' ability to control emotions, manage commitments, and control boredom and procrastination while studying Kanji. Moreover, when learners reach an advanced level, they are more likely to lose their ability to self-adjust due to their inferiority complex because they have not made any progress in learning, or be unable to achieve set goals. This study improves the understanding of the difficulties faced by Japanese learners and offers suggestions to reduce the burden of learning Kanji for students [4].

Although Kanji is widely recognized as the most difficult hurdle to overcome in learning Japanese language, very little research has been done on choosing the Kanji characters and the order to teach Kanji to Japanese language students without a Kanji background. This study analyzes the criteria of differences in Kanji order of learning what benefits in teaching Kanji to non-Kanji Japanese students. In general, the order in which the Kanji are taught seems to be largely random and is not of great importance in supporting students to reach a certain level of Kanji. The article examines the difficulty of Kanji for those without a Kanji background and finds that Kanji order is actually an important factor in developing more effective Kanji teaching and learning strategies for students without a Kanji background [5].

For language learners, when contacting another language at elementary level, the four skills of listening, speaking, reading and writing play an important role. In particular, for beginners, there are many difficulties because their vocabulary and grammar are not many. Moreover, Japanese has three alphabets: Hiragana, Katakana and Kanji, among which Kanji practice should be carried out in parallel with other 
skills from the beginning. Moreover, practicing Kanji right from the beginning of Japanese language helps learners quickly increase their vocabulary [6].

For Japanese language learners, Kanji has always been seen as the toughest barrier. Each different level of study will have the number of Kanji equivalent to that level. Up to now, the number of common Kanji is about over 2000 characters. Each kanji, when standing alone, has many different ways of reading and when it is combined with another Kanji, there will be a different ways of reading. Therefore, to be able to Kanji correctly and skillfully, the learner needs to have extensive knowledge of Japanese. Currently, although there are a lot of Kanji books that are carefully compiled; However, the higher the level Japanese learners reach, the more Kanji need to be remembered, then just study to remember a huge number of 2000 common Kanji will be very difficult. Therefore, the fastest and longest way to memorize Kanji is to apply learned Kanji in practice, through reading books, watching movies or in dialogues [7].

\subsection{The most common methods of learning Kanji currently}

Through the survey, the article has summarized seven methods that Vietnamese students often apply when studying Kanji. These methods are learning Kanji via smartphone apps, learning by memorizing images, learning in a radical order, learning Kanji in an order from simple to complex, learning by Sino-Vietnamese pronunciations, learning Kanji by rewriting and learning Kanji by using flashcards.

The method of learning Kanji via flashcard is to use small cards. Each card has the information about a Kanji such as the typeface, meaning, Sino-Vietnamese pronunciations, On-Kun syllables and the words written with that Kanji. The SinoVietnamese method of learning Kanji is the parallel learning of Japanese with SinoVietnamese pronunciation of each Kanji. Learning kanji in order from simple to complex is starting to learn from Kanji with less writing and more use in daily life to Kanji with more difficult handwriting and less common use. The method of learning radicals is to memorize the basic sets of Kanji before learning Kanji or in parallel with learning Kanji. The association method is to learn Kanji by associating a typeface with an image that has similar features and meaning to that Kanji. Learning Kanji via mobile app is to take advantage of free or paid apps available on your phone for learning, with applications such as Kanji learning apps, Kanji face recognition in the form of multiple choice questions or even online flashcards [9].

Ngoài ra, bài viết còn tìm hiểu được một vài phương pháp học Kanji ít phổ biến. Các phương pháp này là học qua các phương tiện giải trí như truyện tranh hay phim ảnh và sử dụng phương pháp mà trẻ em người Nhật được dạy Kanji $[8,9]$.

Additionally, the article also finds some less popular Kanji learning methods. These methods are learning through recreational media such as comics or movies and using the method in which Japanese children are taught Kanji [8, 9]. 


\subsection{Analysis and comparison of Kanji learning methods}

\subsubsection{Method of learning Kanji via flashcards}

This is one of the most popular methods to learn a foreign language, not just Kanji or Japanese. The advantage of this method is that learners can create their own flashcards with just a few small pieces of paper, which is very convenient to carry. With this method, learners can practice Kanji anywhere [9]. While you can save time by buying pre-made flashcards, making your own flashcards is also a useful way to learn. However, with the advent of smartphones and countless free kanji learning apps, including flashcard apps, the convenient compactness of traditional flashcards has become somewhat cumbersome. This is also the reason that this method is not too popular with teenage Japanese learners.

\subsubsection{Method of learning Kanji by learning Sino-Vietnamese pronunciations}

This is also one of the most popular methods for Vietnamese people when learning Japanese language. Although Vietnam does not belong to the countries using Chinese characters, but it is a country in the area of Han culture. It means that the number of Vietnamese words derived from Chinese characters, also known as Sino-Vietnamese, is large [8]. Therefore, the biggest advantage of this method is that it helps Vietnamese people learn Kanji from elementary to intermediate level very quickly and highly effects towards the Kanji language learning beginner. However, due to it, there is also a great advantage, which is the need to remember a lot of SinoVietnamese sounds in parallel with having to memorize a huge amount of On and Kun syllables. However, not all Kanji have Sino-Vietnamese sounds close to its meaning, and there are also many uncommon Sino-Vietnamese words.

\subsubsection{Method of learning Kanji in order from basic to complex}

This should be called a principle when learning Kanji rather than a method of learning [5]. By starting from the basic Kanji, few strokes will help beginners learn quickly, remember more easily, thereby give learners a sense of confidence when learning a language [4]. On the contrary, if learners start learning from complex, they will quickly become depressed and it will have negatively affects on their learning performance, as author H. Rose said [4].

\subsubsection{Methods of learning radicals}

Each radical itself is also a Kanji and the morphological change allows many Kanji to be put together to form new words having the meaning a partial similarity to the radical. The advantage of this method is that it helps learners to analyze the meanings of Kanji based on the radical or guess the meaning of unknown Kanji, which is beneficial in memorizing Kanji and reading texts. Furthermore, although the number of common Kanji can be more than 2000, the total number of radicals in Japanese is only 214, and only about 30 sets of opponents are needed for elementary Kanji [5]. However, this is very useful for Japanese learners of intermediate level and above. For the beginner, the need to memorize more radicals will be complicated and difficult [3]. 


\subsubsection{Associative method}

The method of memorizing Kanji through images, also known as the association method. Kanji are originally hieroglyphs, meaning words created based on the simulation of images of objects. With this method, learners are able to quickly memorize Kanji by associating them with the original image that the Kanji is based on. For more complex Kanji, users can think back from the available scripts to imagine a similar action and image [7]. With this method, Japanese learners at all levels can apply, but there is a disadvantage that this method will depend on each person's imagination.

\subsubsection{Method of rewriting Kanji}

The method of writing Kanji over and over again, is also known as Rote learning. With this method, learners only need to rewrite the Kanji many times, combined with the silent reading of On and Kun syllables and the simplest meaning of that Kanji [6]. The strength of this method is that it helps learners have the ability to memorize text typefaces, writing styles, sounds and meanings of Kanji for a long time, in addition to helping learners increase the ability to hand-note texts. The most notable downside in this method is that it is extremely time consuming and easy to make learners feel bored [3].

\subsubsection{Method of learning through applications on smartphones}

In the era of industrial science development today, the smartphone has become an indispensable tool in life [7]. Learners can easily find a useful Japanese learning application that can replace traditional flashcards, and a Kanji writing practice application, an application to look up any questions encountered when learning Japanese through online search engines without costs [8]. Even there are applications linked via social networks to exchange learning with other Japanese language learners in remote places. Smartphones can be an extremely convenient and useful learning tool, but they can also become the biggest distraction for learners [4].

\subsection{Research methodology}

This research paper is written based on data from a survey at FPT University in Ho Chi Minh City in September 2020. The survey subjects include 14 students in the 3rd and 4th years who are currently majoring in Japanese language at different levels. There is one N1-leveled student, four N2-leveled students, seven N3-leveled students and two N4-leveled (Figure 1). 


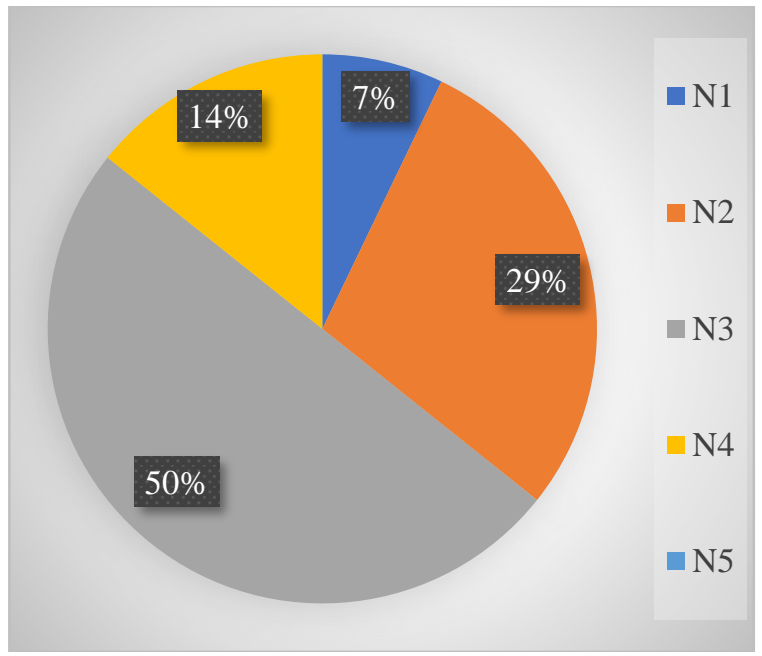

Fig.1. Current Japanese language proficiency of the particpants.

Regarding the Japanese language proficiency of surveyed students, $7 \%$ of students have N1 Japanese language proficiency, 29\% of students have N2, 50\% of students have N3, and $14 \%$ of students have N4. Therefore, most of the respondents have N3 Japanese language proficiency (Figure 2).

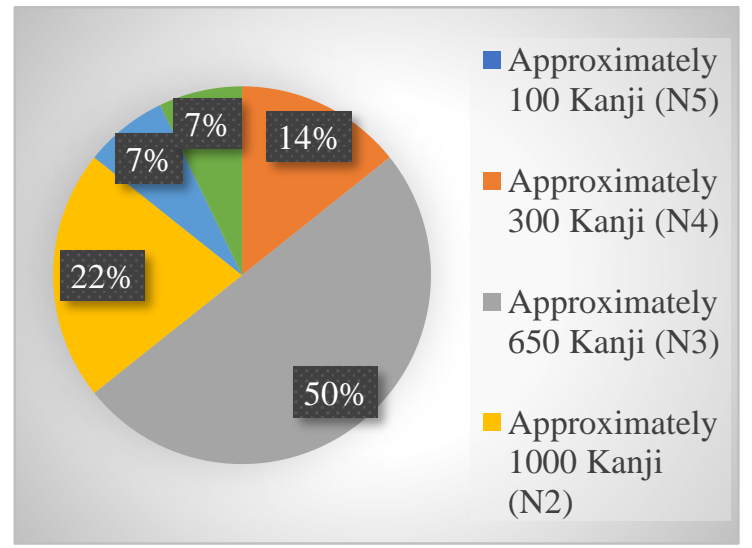

Fig.2. Level of Kanji characters.

\subsection{Results and discussion}

Followings are the survey results of Japanese language students at FPT University about Japanese language proficiency, Kanji levels and Kanji learning methods that students are currently applying. 


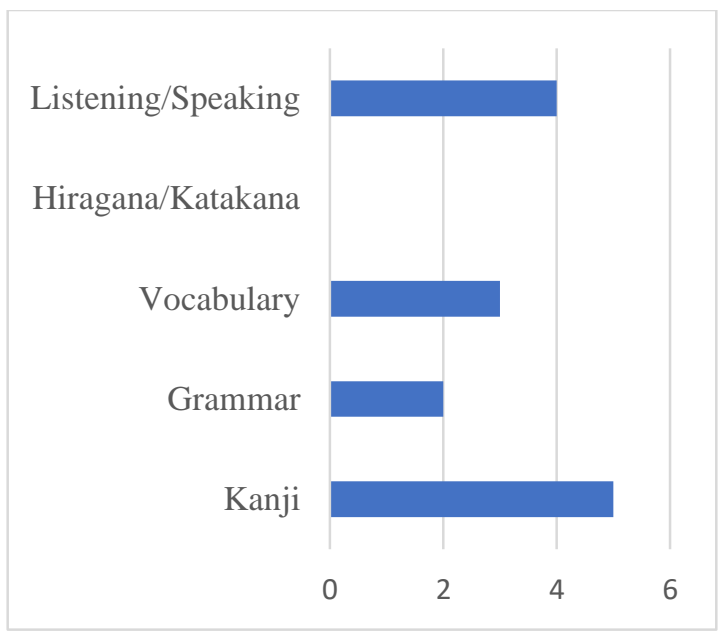

Fig.3. Most common difficulties of learning Japanese language.

In figure 3, the highest choice for the question "What is the biggest difficulty in learning Japanese?" There are 5 people choosing "Kanji". The second is Listening / Speaking with 4 choices. Nobody thinks the Hiragana and Katakana alphabets are a difficulty when learning Japanese (Figure 3).

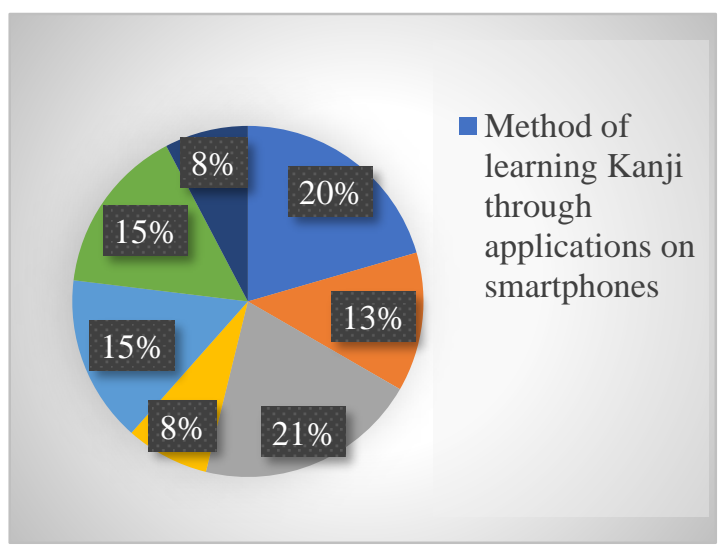

Fig. 4. Kanji learning methods currently applied by Japanese language learners.

In Figure 2, it can be seen that the two most commonly used Kanji learning methods by Japanese learners are learning through the Kanji learning apps on smartphones $(20 \%)$ and the association method $(21 \%)$. The next is the radical learning method and learning Sino - Vietnamese pronunciations (15\%). It can be seen that the respondents pay much attention to modern learning methods such as using mobile apps and using less traditional learning methods such as rewriting Kanji and using flashcard (Figure 4). 


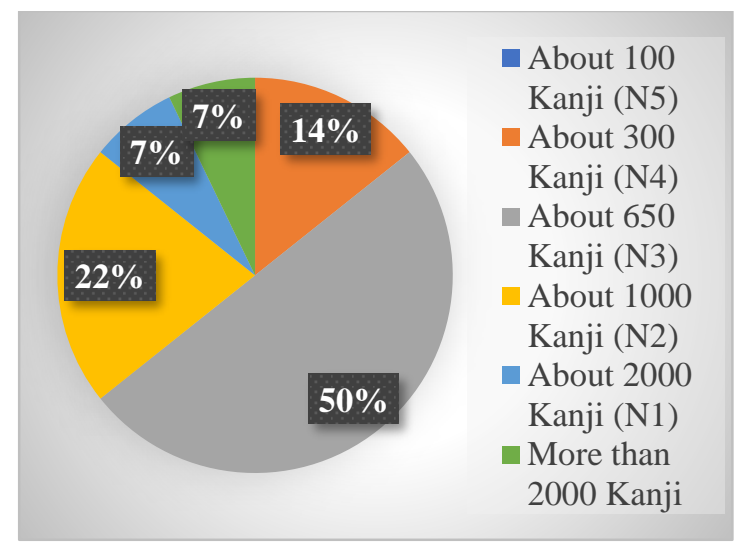

Fig.5. Current Kanji levels.

According to the survey results from Figure 4, there are $7 \%$ of students with Kanji level of more than 2000 characters, $7 \%$ of students at Kanji level of about 2000 characters, 3 students with 1000 characters, 7 students with 650 Kanji and 2 students with 300 Kanji. It can be seen that respondents' average Kanji level is higher than their Japanese proficiency. This reflects that students really focus on learning Kanji (Figure 5).

\subsection{Methods of improvement}

Through the analysis and comparison of the current Kanji learning methods of Japanese learners, the article gives some suggestions to help learners of Kanji at elementary level to improve their Kanji learning ability and efficiency [9]. First, to increase learning efficiency and performance, learners should not force themselves to study too much, study continuously for a long period of time. It is advisable to divide the school day equally [4], with a specific schedule. Setting this plan also brings great benefits. Once the learners complete their own plan, it will create a sense of confidence for learners because they have completed their own goals, thereby motivate themselves. The learners should set new goals and plans and accomplish them. Learners should not study alone as well. Joining groups or review clubs to exchange experiences with others will procduce effectiveness. Learning from others is also a good way to acquire new knowledge and guide others to practice on your own [8].

They should combine many learning methods together to have the highest learning efficiency. For example, when applying the Kanji rewriting method, learners can combine with the association method and learn more Sino-Vietnamese pronunciations, thereby it helps reduce the disadvantages of the boredom of sitting and writing Kanji as well as helps learners remember Kanji characters longer [10]. When applying one or more learning methods, it is important that the learners should review old Kanji characters in parallel with learning new Kanji characters as when the learners reach higher levels, the more Kanji they need to learn, then it is inevitable to forget about old Kanji characters that are less commonly used [11]. In addition, the teacher should also learn the method of teaching Kanji for Japanese students applied in schools in Japan. Japanese children are taught Kanji by writing practice [9]. 
Besides, each Kanji will have a small story pattern and a corresponding photo, then for each Kanji being taught, students will put one to two sentences by using the learned Kanji characters. The learners should not study single Kanji, but combine learned Kanji to form words and learn Kanji in pairs. This not only helps the learners review old Kanji characters along with the new ones, but also helps them increase their vocabulary. It is recommended to use Kanji regularly in many simple ways such as reading Japanese manga [12], watching movies with Japanese subtitles, reading news on NHK homepage or maybe writing daily diary to increase the ability to use Kanji.

\section{Conclusion}

The above article has summarized popular Kanji learning methods of Vietnamese students. In the above methods, depending on each person, there will be different appropriate methods. The learners should try each method to find the most effective way for themselves. The most important thing when learning Kanji is to be patient. In the first time exposing to Japanese language, Vietnamese people, from a country with alphabetic language, are easily overwhelmed when faced with Kanji, or feel discouraged and give up. Kanji is not difficult but it is extremely time consuming.

\section{References}

1. S. Writer, Japan reveals 87 projects eligible for "China exit" subsidies. Nikkei Asia, https://asia.nikkei.com/Economy/Japan-reveals-87-projects-eligible-forChina-exit-subsidies

2. K. Matsumoto, Mod. Lang. J., 01426x (2013)

3. S. Van Aacken Int. J. Phytoremediation, (1999)

4. H. Rose, L. Harbon, Foreign Lang. Ann., 12011 (2013)

5. S. Paxton, C. Svetanant, Int. J. Res. Stud. Lang. Learn., 519 (2013)

6. E. Toyoda, Electronics Journal of Foreign Language Teaching, 6(1), 5 (2009)

7. D. Nesbitt, New Zealand Studies in Applied Linguistics, 15(2), 61 (2009)

8. T.T.K.Tuyen, VNU Journal of Foreign Studies, 35(5) (2019)

9. V.T. Trần, D.T. Nguyễn, Quy tắc học Kanji trong tiếng Nhật,-2, 24 (2012)

10. S. Matsunaga, Japanese Language and Literature, 55(1), 390 (2021)

11. H. Yamashita, Y. Maru, The Journal of the Association of Teachers of Japanese, 34(2), 159 (2000)

12. T. Nakayama, Japanese Psychological Research, 63(1), 26 (2021) 